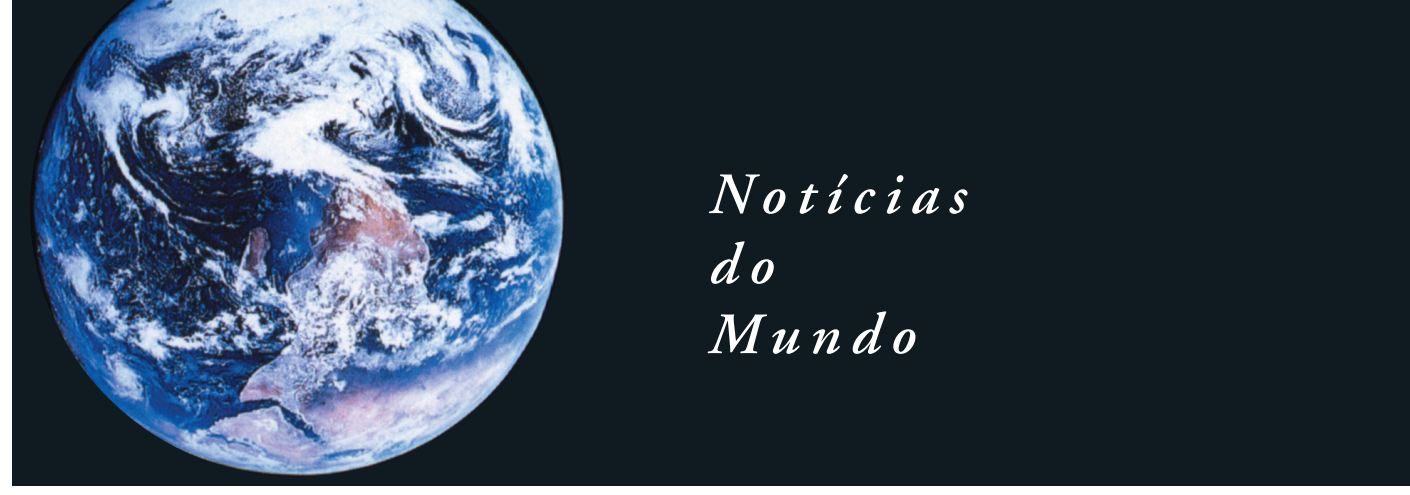

Antropologia

\section{Redes sociais conectam vida pessoal a profissional}

Faz parte da natureza humana o convívio com outros indivíduos e grupos de afinidades diversos. Esta interação tem se modificado através dos tempos, seja pela necessidade de sobrevivência material, seja movida pelas angústias pessoais ou por premências econômicas, sociais e políticas. $\mathrm{O}$ poder de interconexão dessas relações sociais, nas últimas décadas, foi potencializado a patamares dificilmente imaginados, pelo surgimento das tecnologias de informação e comunicação (TICs), em particular as que possibilitam a operação das redes sociais da internet. $\mathrm{O}$ impacto dessas relaçóes transbordou para o mundo real: os papéis sociais já não têm divisões claras.

"O tempo das pessoas está se comprimindo. Isso implica no fato de que as pessoas estão misturando suas vidas, no trabalho, nas socializações e nas horas de lazer”, explica Marcos Cordiolli, pesquisador da área de educação e consultor pedagógico sobre educação corporativa. Por um lado, diz, essa falta de limites claros é positiva, pois desenvolve e exercita as capa-

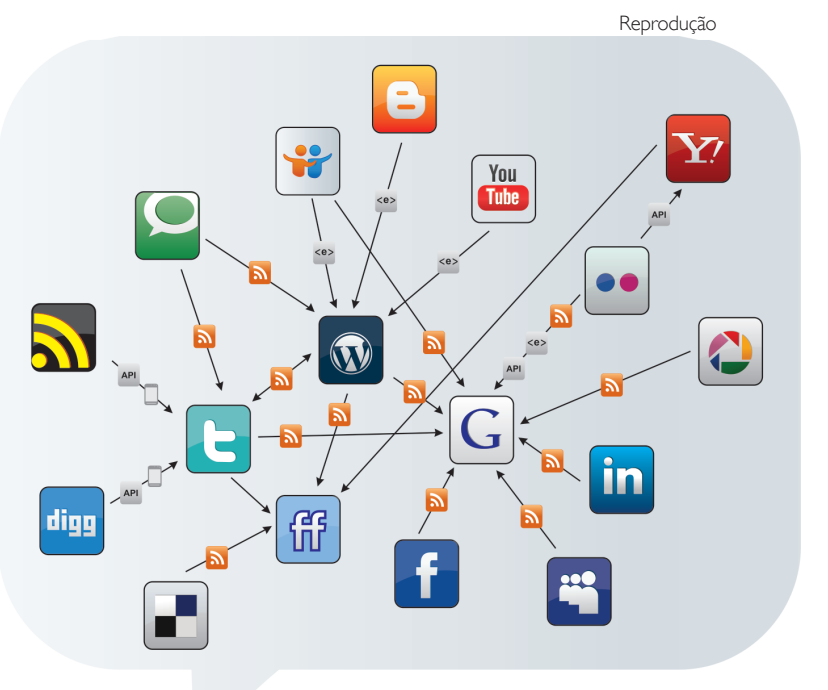

Algumas das principais redes sociais no Brasil

as pessoas no ambiente de trabalho, agora não consegue mais ser esses dois personagens tão diferentes", afirma o pesquisador.

"Um profissional pode conversar com pessoas de lugares distantes e, mesmo assim, ter intimidade com essas pessoas. As fotos dos momentos felizes, da família estão no Facebook, no Flickr ou no Picasa" aponta Cordiolli. "É como se tivéssemos

cidades de socialização dos indivíduos, tornando possível interagir de forma mais refinada, aprender a respeitar as diferenças entre as pessoas e identificar diferentes pontos de vista. Por outro lado, para alguns, isso pode significar uma crise de identidade.

Cordiolli lembra que existem diferentes papéis sociais para cada ocasião e, portanto, cada um se porta de modo distinto nos diversos espaços de convívio social. "Entretanto, quando se está em uma rede social na internet, de forma pública, todos veem nossas diversas facetas. Uma pessoa que é intransigente no dia a dia e que, antes do advento dos perfis públicos na internet, conseguia se equilibrar na hora de lidar com uma vivência íntima sem nunca ter estado com esses indivíduos. Em outros casos é possível trabalhar conjuntamente, escrever textos em coautoria, organizar e intervir no trabalho do outro simultaneamente, como se fosse um diálogo frente a frente", completa o especialista. É também comum que o trabalho seja o centro das relações sociais, o centro da espiral de socialização e, muitas vezes, direcione para onde esse círculo social se expandirá. Mas isso pode acabar sendo uma vantagem para o trabalhador, que acaba, literalmente, criando um networking ativo.

"As empresas, parece, estão se apropriando não só da força física do trabalhador, mas também 


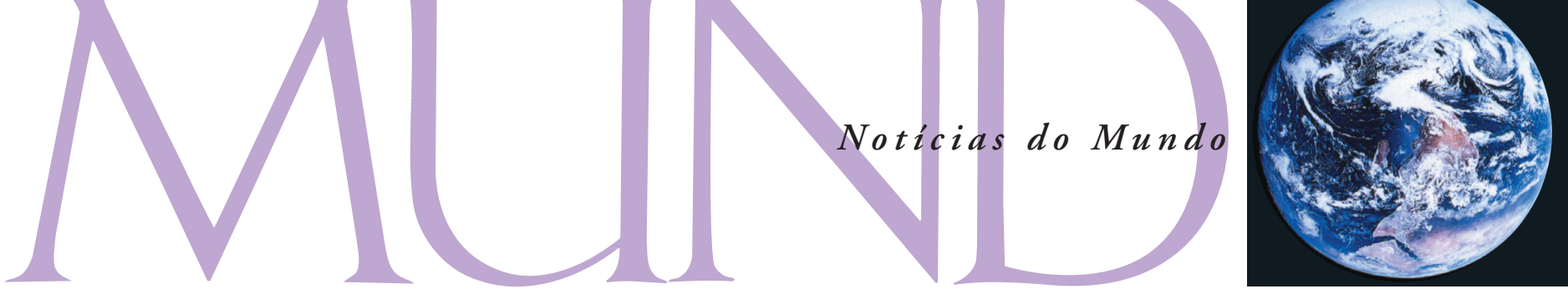

\section{DADOS DA INTERNET NO BRASIL E NO MUNDO}

De acordo com pesquisa publicada pelo instituto lbope/ Nielsen, o número de internautas com mais de 16 anos no Brasil era de 73,9 milhões no final de 2011, e seis meses depois atingiu cerca de 82,4 milhões. Em 2003, esse número era de 19 milhões. Os sites de educação e carreiras responderam, no início deste ano, pelo maior número de acessos únicos: 25,8 milhões de usuários (ou 34,9\%). A categoria de comunidades, que engloba os sites de redes sociais, fóruns e blogs alcançou 39,3 milhões de usuários brasileiros em agosto de 2010, o que equivale à 53\% dos internautas ativos.

Até $2015,80 \%$ dos lares brasileiros poderão dispor de internet, segundo o Comitê Gestor da Internet (CGI.br). Atualmente, aproximadamente $40 \%$ deles estão conectados, um número abaixo dos de padrão europeu, que já ultrapassou a média de $67 \%$ (dados do relatório do painel da Comissão Europeia). Em abril deste ano, o Facebook somou 40 milhões de usuários no Brasil, ante 27 milhões do Orkut e 11 milhões de contas ativas no Twitter, de acordo com o lbope/Nielsen. A ComScore, consultoria especializada em internet, analisa que apenas o crescimento do Facebook, no Brasil, até fevereiro deste ano, foi em torno de 250\%. Já o Linkedin (rede social de profissionais que soma 150 milhões de usuários no mundo) afirma ter chegado a 4 milhões de usuários no país, $428 \%$ de crescimento em um ano. Em todo o mundo esses números de crescimento são menores, pois já se atingiu a estagnação e o crescimento mais lento. $\mathrm{Na}$ Alemanha, por exemplo, um dos países da Europa que mais crescem no uso do Facebook, a alta de usuários foi puxada pelas mulheres com mais de 45 anos, que aumentaram em 39\%. Todos as outras faixas etárias e de gênero se mantiveram abaixo dos $25 \%$. Bem longe do boom brasileiro. da sua vida pessoal. É uma forma de competir com outras empresas e serviços, se aproveitando do engajamento nas redes sociais que o trabalhador - agora 'colaborador' - já teceu a partir dos seus contatos pessoais, que são, então, assimilados pelos patrões", explica José Dari Krein, pesquisador do Centro de Estudos Sindicais e de Economia do Trabalho do Instituto de Economia da Universidade Estadual de Campinas (Unicamp). Ele enfatiza que já não é possível deixar a vida individual descolada da profissional. "Antes se trabalhava para viver, hoje se vive para trabalhar; e os mecanismos de controle sobre os trabalhadores/colaboradores estão ficando mais sofisticados, a ponto dos patrões saberem como seus contratados agem ou pensam, apenas observando sua vida nas redes sociais".

Duas pesquisas recentes mostram a intensificação da inter-relação entre o profissional e o pessoal. Uma delas, feita por Kelly MacKay, da Universidade de Ryerson, no Canadá, e Christine Vogt, da Universidade Estadual de Michigan, nos EUA, observa que muitos profissionais, mesmo de férias, têm cada vez mais dificuldades de se desconectar dos seus gadgets tecnológicos. Outra, feita por Helena Johnson, da Sociedade Certificada de Fisioterapia da Grã-Bretanha, aponta que é cada vez mais comum que funcionários façam hora extra fora do local de trabalho.

Essa fusão entre vida pessoal e profissional, lembra Krein, se reflete nas chamadas doenças do século XXI, como a depressão, a ansiedade e o estresse. "As pessoas estão buscando formas de lidar com essa fusão que permeia a vida de todos que estão no mercado de trabalho", conclui.

Enio Rodrigo Barbosa 